\section{Reimaginar el laicado desde la teología pastoral de Manuel Larraín*}

\author{
Sandra Arenas** \\ Paula de la Cerda***
}

RECIBIDO: 19-10-16. APROBADO: 06-02-17

Resumen: "Lo secular es lo propio del laicado". Esta afirmación conciliar resonaba en el pensamiento teológico-pastoral del obispo chileno Manuel Larraín, un buen impulsor del desarrollo de una teología del laicado ajena a cualquier eclesiocentrismo. La teología de las realidades temporales y de la historia previa al Concilio marcará transversalmente su contribución conciliar en estas materias. Este artículo muestra cómo una teología positiva del laicado necesita de un renovado paradigma eclesiológico y de una teología positiva de la historia. Desde algunas fuentes archivísticas, la interconexión entre las tres teologías en juego son revisitadas desde el pensamiento de Larraín en el periodo conciliar, para explorar sus potencialidades en la actual agenda eclesial.

PAlabras Clave: Laicado, apostolado laical, Manuel Larraín, teología de la historia, Concilio Vaticano II, eclesiología.

\section{Reimagining Laity from Manuel Larrain's Pastoral Theology}

AвSTRACT: "What specifically characterizes the laity is its secular nature". This conciliar postulate has strongly resonated within the theological and pastoral thought of the Chilean Bishop Manuel Larrain. He is one of the greatest contributors to the development of a Theology of the Laity that goes far beyond any ecclesiocentric paradigm. Two preconciliar theologies, the Theology of Earthly Realities and the Theology of History affected transversally Larrain's conciliar contribution on these matters. This article shows how a positive Theology of the Laity requires a renovated ecclesiological model and a positive Theology of History. From several archival sources, the interconnection between the three theologies which are at stake will be reviewed from the perspective of Larrain's thought during the conciliar period, in order to explore their potentiality in the current ecclesial agenda.

KeY WORDs: Lay apostolate, Manuel Larrain, Theology of history, Second Vatican Council, ecclesiology.

PARA CITAR ESTE ARTÍ́CULO:

Arenas, Sandra y Paula de la Cerda. "Reimaginar el laicado desde la teología pastoral de Manuel Larraín". Theologica Xaveriana 184 (2017): 285-308. https:// doi.org/10.11144/javeriana.tx67-184. rltpml

*Artículo fruto de la investigación titulada "Contribución de Chile al Concilio Vaticano II. Indagación en sus fuentes”, financiado por el Consejo Nacional de Ciencia y Tecnología, Conicyt, de Chile. Proyecto Fondecyt 11140315 (2015-2017).

* SAndra Arenas: Doctora en Teología Sistemática, KU Leuven, Bélgica. Profesora de planta, Facultad de Teología, Pontificia Universidad Católica de Chile, PUC. OrCid: 0000-0002-4374-0872. Correo electrónico: searenas@uc.cl/

${ }^{* * *}$ Paula de la Cerda: Bachiller en Teología, Pontificia Universidad Católica de Chile, PUC, Santiago. Investigadora asistente en el proyecto "Contribución de Chile al Concilio Vaticano II. Indagación en sus fuentes”; asistente de investigación, Centro de Estudios de la Religión de la PUC. OrCiD: 0000-00016439-4967. Correo electrónico: padelacerda@uc.cl 


\title{
Introducción
}

Uno de los obispos chilenos que más aportó en la sistematización y comprensión de la vocación laical en los debates conciliares fue sin duda Manuel Larraín Errázuriz (1900-1966)', quien colaboró especialmente en el proceso de redacción del decreto Apostolicam actuositatem. Don Manuel profundizó en estas materias gracias a su participación activa en la Acción Católica Chilena. Desde 1933 fue uno de sus primeros asesores, y entre 1952 y 1962, su asesor nacional.

En dicha época -según sostuvo luego el propio Larraín-, por medio de esta organización la Iglesia maduró su comprensión del estado laical ${ }^{2}$. En efecto, la Acción Católica Chilena enriqueció su comprensión de la naturaleza y misión del laico, determinando tanto su modelo de Iglesia como su teología de la historia. Esta evolución siguió los siguientes pasos: (1) Asumir al laico como un mero ejecutor de los mandatos de la jerarquía; (2) considerar su apostolado como una participación en la misión de la jerarquía y un complemento al sacerdocio ministerial; (3) entender su misión como respuesta a un llamado de la jerarquía; (4) definirlo positivamente como alguien responsable de su vocación evangelizadora, apostólica por su origen sacramental.

Este artículo considerará tal evolución y sus resultados, como el presupuesto sobre el cual es posible -desde el pensamiento teológico-pastoral de Larraín- desarrollar una equilibrada teología de Iglesia y de la historia. En lo que sigue, revisaremos estas teologías en dos clases de fuentes:

- Tres discursos en aula conciliar compendiadas en Acta Synodalia ${ }^{3}$ y recientemente traducidas al castellano ${ }^{4}$.

- $\quad$ El corpus epistolario del periodo conciliar. ${ }^{5}$

\begin{abstract}
${ }^{1}$ Nacido en Santiago, se educa en el colegio jesuita San Ignacio, donde conoce al amigo de toda su vida Alberto Hurtado Cruchaga, sacerdote jesuita, santo chileno. Como seminarista diocesano realiza sus estudios de teología en la Universidad Gregoriana de Roma. En 1939 es nombrado obispo de Talca. Por diez años es asesor nacional de la Acción Católica Chilena. En 1957 expone, en el Congreso Mundial del Apostolado Laico, en Roma. En 1960 es nombrado consultor de la Comisión para el Apostolado de los Laicos por Juan XXIII y luego es miembro de esta comisión. Junto a Helder Cámara cofunda la Conferencia del Episcopado Latinoamericano, y en 1964 es escogido presidente de la misma. Participa activamente como padre conciliar en las cuatro sesiones del Concilio, especialmente desde la Comisión Conciliar del Apostolado Laico.
\end{abstract}

${ }^{2}$ Larraín, Escritos completos. La Iglesia en su vida intima, 267.

${ }^{3}$ Ídem, en Acta Synodalia Sacrosancti Concilii Oecumenici Vaticani II, Vol. II, periodus II, pars III (23 de octubre de 1963), 223-226; Vol. III, periodus III, pars IV (12 de octubre de 1964), 184-186; Vol. IV, periodus IV, pars III, 373-375 (5 de octubre 1965) [originales en latín, traducción propia no publicada]. Para estas fuentes usaremos la abreviatura $A S$.

${ }^{4}$ La traducción del corpus completo de las intervenciones de los obispos chilenos en el Concilio Vaticano II, es parte del Proyecto Fondecyt en curso, cuya referencia se encuentra en la nota inicial.

${ }^{5}$ Ubicado en el Archivo del Obispado de Talca (en proceso de clasificación, no publicado). No se utilizaron 
El lector puede esperar entonces una exposición de la teología del laicado en Larraín, que en primer lugar determinará el modelo de Iglesia que se reconfigura en su ejercicio pastoral y teológico; en segundo lugar, buscará una renovada comprensión de las realidades terrenas como positiva teología de la historia; (3) revisará luego algunos ecos de esa teología del laicado en el caso chileno; y (4) finalmente, presentará reflexiones conclusivas tendientes a reimaginar el laicado desde la contribución conciliar del obispo de Talca.

\section{Teología del laicado en Manuel Larraín}

La evolución que experimentará la identidad laical, en el sistema teológico-pastoral de Larraín, condicionará su mirada eclesial de roles, pertenencia y estructuras. Resulta muy revelador, en este proceso, el hecho de que su penetración intelectual será consecuencia de la praxis en el movimiento laical en el que comprometió su servicio ministerial.

No era extraño, en el periodo preconciliar, situar al laicado en una condición dependiente y al servicio de la jerarquía eclesiástica, sin identidad apostólica propia. Recordemos que en los pontificados de Pío XI y Pío XII -europeocentrados como los anteriores- se tomaron acciones estratégicas para definir la presencia de la Iglesia en los estados europeos que lidiaban entre las ideologías nacionalistas y las comunistas ${ }^{6}$.

En dicho contexto se crea la Acción Católica, basada en el catolicismo social del siglo XIX 7 . De esta manera, en la primera mitad del siglo XX, contexto inmediato del Concilio, no hubo espacio de autonomía oficial para la participación de los católicos en la arena pública, ni para desarrollar autónomamente profundizaciones teológicas en los movimientos de renovación ${ }^{8}$. No obstante, la Acción Católica incorporó aires de renovación teológica y preparó líderes para difundir dicho impulso teológico.

Algo de esta vertiente determinó que el Concilio desarrollara una teología del laicado emparentada con el movimiento de renovación laical del pre-Concilio. ${ }^{9}$ En

en la elaboración de este artículo, otros trabajos (tesis, libros u otros) basados en la obra Manuel Larraín. Escritos completos, editada por Pedro de la Noi, quien tuvo acceso a algunas de las fuentes que acá utilizamos. Aunque las autoras conocen ampliamente esa literatura secundaria, su opción fue utilizar directamente las fuentes o la obra de Pedro de la Noi.

${ }^{6}$ Ver a Ferrari, Una storia dell'Azione cattolica. Gli ordinamenti statutari da Pio XI a Pio XII.

${ }^{7}$ Frente a un movimiento obrero autoconsciente y al socialismo con pretensiones de representación de ese grupo social, el catolicismo reaccionó oscilando entre impulsar el compromiso social, por un lado, y defenderse de las influencias socialistas y especialmente comunistas, por otro. Ver el buen trabajo de Stuven, "El 'Primer catolicismo social' ante la cuestión social: un momento en el proceso de consolidación nacional", 483-497.

${ }^{8}$ Ver a Steinmaus-Pollak, Das als katholische Aktion organisierte Laienapostolat: Geschichte seiner Theorie und seiner kirchenrechtlichen Praxis in Deutschland.

${ }^{9}$ Para una mejor comprensión ver a Congar, Jalons pour une théologie du laïcat. 
esta incipiente consideración intraeclesial del lugar del laico, Larraín dio un paso adelante al sostener que el apostolado laical debía ser visto como una participación y un complemento del apostolado de los ministros ordenados, con lo cual estableció teológicamente la distinción entre el sacerdocio ministerial y el bautismal, distinción que sería recibida por el Concilio.

Contrastan en este proceso evolutivo de revalorización del ámbito eclesial laical los escritos de Larraín de las décadas de los años 50 y de los años 60. Al referirse a la diferenciación de funciones, roles o carismas entre un sacerdocio y el otro, leemos:

La Acción Católica es primariamente apostolado, lo que significa que ella es participación y colaboración a la acción pastoral del Obispo [...]. El apostolado que es uno en su origen y en su fin tiene, pues, dos órganos para ejercitarse: el eclesiástico y el laico; el uno de derecho divino; el otro, de colaboración a dicho apostolado jerárquico. Diferenciación clara, que de una parte muestra al seglar la grandeza de la misión que le corresponde desarrollar y de otra señala al sacerdote la inmensa fuerza que viene en su ayuda, no para limitar su apostolado, sino para completarlo y dar a esa función su pleno desarrollo. ${ }^{10}$

Para Larraín, la actividad ministerial y la propiamente laical son idénticas en su fin, y su horizonte es historiar la actividad apostólica de la Iglesia, pero difieren en su campo de acción con las formas apropiadas a cada uno de sus ámbitos particulares. El laicismo podría tender a independizar a los seglares y el clericalismo podría llevar a la jerarquía a invadir el campo propio del laico ${ }^{11}$.

La intensa praxis pastoral del obispo de Talca, junto a la determinada evolución teológica en ciertos ambientes eclesiales europeos de los cuales fue deudor, lo llevó a abordar la cuestión laical desde la teología vocacional, mediada en un primer estadio por la jerarquía; y la misión laical fue entendida como la respuesta a un llamado de la jerarquía que actuaba en nombre de Dios:

...sin tocar en nada el patrimonio de la jerarquía y clero, y en íntima unidad con ellos, el laicado oye el llamado de la Iglesia que, mostrándole esos ambientes profanos, les hace sentir la responsabilidad apostólica de ellos y les confía la sublime tarea de establecer la Iglesia en los medios de vida en que concretamente y por destinación providencial están ligados. ${ }^{12}$

De la praxis eclesial se desprende una mayor densidad histórica y consistencia secular. Desde ahí Larraín define positivamente al laico como un sujeto eclesial, con

\footnotetext{
${ }^{10}$ Larraín, Acción Católica y realidades modernas, 8-13; ídem, Escritos completos. La Iglesia en su espiritualidad. El laico cristiano, 185-187.

${ }^{11}$ Ibíd.

12 Ídem, Escritos completos. La Iglesia en su vida intima, 217; ídem, "Discurso del asesor general de la A.C. Chilena en la sesión de clausura de la III Semana Interamericana de A.C.”, 1-15.
} 
vocación apostólica de iure, por su origen sacramental, ya que el bautismo y la confirmación lo hacen miembro de un cuerpo que le confía una misión apostólica ${ }^{13}$. De esta manera, se instaló como imperativo formar laicos maduros, capaces de asumir la tarea apostólica en la historia como responsabilidad propia, como adultos en su fe conscientes del encargo eclesial recibido por su vocación sacerdotal bautismal:

[La oración] es la expresión práctica de la paternidad de Dios sobre nosotros. Así, cuando yo llego al puesto tal o cual, al ambiente, llego por causas humanas, pero detrás de esas causas humanas hay Providencia divina. Ahí me quiere a mí, en esa oficina, en ese banco, etc., y cuando llego con esa conciencia cristiana de que llego por vocación divina, sé que tengo ahí una misión que cumplir y que esa misión es una misión de Iglesia; que es la Iglesia que se hace representar por mí oficialmente, seguramente por el párroco. "Esta vocación divina de la Acción Católica, en esa participación de los seglares en el apostolado jerárquico, es como cierta representación de Iglesia que lleva el laico católico". ${ }^{14}$

Se trata de laicos que con proactividad e iniciativa propia se ocupen de los problemas reales de sus ambientes, más allá de la institucionalidad. En efecto, para Larraín la vocación laical debe vivirse plenamente en el mundo, para convertir en armonía la tensión que con frecuencia se presenta entre religión y vida, y hacerle sentir que la plenitud de su vida cristiana se logra, no a pesar de estar en el mundo, sino precisamente por hallarse en él ${ }^{15}$.

El bautismo y la confirmación que han recibido impulsa a los laicos a cumplir esta tarea apostólica ${ }^{16} \mathrm{y}$ a ser proactivos en la formación de $\mathrm{su} \mathrm{fe}^{\mathrm{e}}{ }^{17}$. El desafío reside en santificar lo temporal evitando el riesgo de una suerte de angelismo con concentración exclusiva en lo espiritual ${ }^{18}$. Esta convicción de los años 50 será más plenamente desplegada en las intervenciones de Larraín en el aula conciliar, tan alabadas por el gran eclesiólogo de la época, el dominico francés Yves Congar ${ }^{19}$, entre otros.

${ }^{13}$ Ídem, Hacia una espiritualidad del laicado, 20-28.

${ }^{14}$ Ídem, Escritos completos. La Iglesia en el mundo, 105.

${ }^{15}$ Ibíd., 26-27; ídem, Escritos completos. La Iglesia en su vida intima, 268.

${ }^{16}$ Ídem, Hacia una espiritualidad del laicado, 20-28.

${ }^{17}$ Ídem, Escritos completos. La Iglesia en su vida intima, 467.

${ }_{18}^{1}$ Ídem, El cristiano frente al mundo moderno. El apostolado del ambiente; ídem, Escritos completos. La Iglesia en su espiritualidad. El laico cristiano, 209.

${ }^{19}$ En efecto, en su Diario del Concilio, Congar se refiere a Larraín como uno de los que más entiende la cuestión del apostolado laical. Ciertamente, con él tiene sintonía respecto de la comprensión de naturaleza y misión del laicado y sobre la necesidad de apertura eclesial (Congar, Diario del Concilio, 45-46, 102 y 146). 
Las circunstancias concretas de la vida real de las personas determinarán el apostolado laico. El laicado no se inventa el campo de su misión; esas circunstancias particulares "no están en el aire sino en las condiciones concretas de su existencia, de la familia, de la profesión, de su situación social" ${ }^{20}$. Por deber de estado, el laicado tiene la ocupación de las realidades temporales, para dar inspiración cristiana al mundo $^{21}$. No huye del mundo: antes bien, siente la necesidad de perfeccionarlo, de santificarlo y de santificarse en él ${ }^{22}$, porque Dios actúa en esas realidades terrenas: “...los artesanos inmediatos del Reino de Dios en la vida temporal serán los seglares..." La vida temporal es el lugar insustituible del apóstol laico, dado que "nada humano escapa al límite del apostolado, porque nada es externo a Dios y al ser humano" ${ }^{24}$. Larraín urge a "resituar" e increpa con fuerza al episcopado: "Dejemos a nuestros laicos que actúen. Ellos también son Iglesia”25.

El giro eclesiológico es elocuente: al situar apropiadamente al laico en la comunidad eclesial, se asegura su real inserción en la comunidad civil. Ambos órdenes deben, sin embargo, distinguirse para potenciarse. Es el bautismo y su eficacia lo que finalmente "capacita" al laico para esta tarea, que es una tarea profética en propia regla; una que "implica para todos el importante deber de la predicación y del testimonio" 26 , pues "para esto, el pueblo de Dios está en el mundo, para que muestre el testimonio de la verdad" ${ }^{27}$.

No se trata de un mero deber, sino de una experiencia de encuentro del creyente con Cristo, situado en el marco de una relación personal que se verifica en la historia. La Palabra de Dios impele al ejercicio de la tarea profética ${ }^{28}$, y esa Palabra predicada, autoimplicada indefectiblemente en la tarea profética, no refiere a una desafectada repetición, sino a una asimilación existencial que afecta un estilo de vida.

En el periodo conciliar, Larraín insistirá entonces en que el tria munera sea aplicado de iure al laicado; toda la teología renovada del bautismo del preconcilio ${ }^{29}$

\footnotetext{
${ }^{20}$ Larraín, Escritos completos. La Iglesia en su vida intima, 147.

${ }^{21}$ Ídem, Escritos completos. La Iglesia en el mundo, 149; ídem, Hacia una espiritualidad del laicado, 31-37.

${ }^{22}$ Concilio Vaticano II, AS III, per. iii, p. IV (9), 184-186.

${ }^{23}$ Larraín, El cristiano frente al mundo moderno. El apostolado del ambiente; ídem, Escritos completos. La Iglesia en su espiritualidad. El laico cristiano, 204.

${ }^{24}$ Ibíd., 204.

${ }^{25}$ Ídem, “Carta a monseñor Emilio Tagle, 4 de julio de 1964” (en proceso de clasificación, no publicado).

${ }^{26}$ Concilio Vaticano II, AS II, periodus II, pars III, 223-226.

${ }^{27}$ Ibíd.

${ }^{28}$ Ibíd.

${ }^{29}$ Caso paradigmático es la teología del jesuita alemán Agustín Bea. Para una descripción detallada de la eclesiología bautismal de Bea, ver a Lanne, "La contribution du cardinal Bea à la question du baptême et
} 
respaldará su postura. Ya el 23 de octubre de 1963, frente a la disconformidad sobre el capítulo De populo Dei del esquema De Ecclesia, Larraín se refirió oralmente a que el progreso respecto de los laicos es parte esencial de la renovación de la Iglesia; y sostuvo que la triple función sacerdotal, profética y real es de todo el pueblo de Dios, al desarrollar en particular los temas de la predicación y del testimonio ${ }^{30}$ en sintonía con lo expuesto el día anterior por el obispo panameño Marcos McGrath sobre la insustituible tarea del laico en la consagración del mundo ${ }^{31}$.

El evento conciliar ha acontecido precisamente para esto, para afectar la historia y dejarse afectar por ella: “...una de las grandes tareas del Concilio ha sido -precisamente- el esfuerzo por presentar a la Iglesia encarnada en la realidad histórica. Esta presencia corresponde en primera línea al laicado" ${ }^{32}$.

El ministerio de la predicación es irrenunciable; y el contacto personal que solo puede impulsar el laicado en la arena pública es insustituible, porque "para esto el pueblo de Dios está en el mundo, para que muestre el testimonio de la verdad"33. La fuerza de esta palabra radica en la consagración bautismal que es realmente la vocación ontológica para el testimonio ${ }^{34}$.

Así, Larraín también situará la predicación en los laicos, con lo cual avanza cualitativamente respecto de teologías precedentes. Se trata de generar colaboración de dos estados de vida diversos, ninguno mejor que otro: "Muchos y santos sacerdotes, sí; pero muchos y apostólicos seglares también. Para transformar los ambientes necesitamos apóstoles de ellos [...]. El equipo sacerdote-laico es el equipo apostólico de hoy" ${ }^{35}$.

En este punto del relato podemos afirmar que la evolución en la comprensión de la naturaleza y misión del laicado definió en Larraín la teología positiva de la historia y una eclesiología equilibrada, aunque la progresión teológica acontecería prácticamente en paralelo. Revisemos las notas características de su eclesiología y de su teología de las realidades temporales para ilustrar mejor esta narrativa.

l'unité des chrétiens", 474-475. Sobre las consecuencias ecuménicas de esta eclesiología revisar a Witte, "The Question of Baptism and the Unity of Christians", 223-230.

${ }^{30}$ McGrath, "Segunda Sesión del Concilio Ecuménico Vaticano II, CECH”. Archives University of Notre Dame, Collection Marcos McGrath CMCG 16/05, 4. 4 de diciembre de 1963.

${ }^{31}$ Ídem, "Los laicos en la Iglesia”. Archives University of Notre Dame, Collection Marcos McGrath CMCG 5/04, 4 (22 de octubre de 1963). Larraín y McGrath habrían establecido una amistad estrecha antes del Concilio, cuando el último desarrollaba tareas de docencia en la Facultad de Teología de la Pontificia Universidad Católica de Chile.

${ }^{32}$ Larraín, Escritos completos. La Iglesia en su vida intima, 136.

${ }^{33}$ Concilio Vaticano II, $A S$, II, periodus II, pars III, 223-226.

${ }^{34}$ Íbíd, $A S$ II, periodus II, pars III, 223-226.

${ }^{35}$ Larraín, Escritos completos. La Iglesia en su vida intima, 30; ídem, “Testamento pastoral”. 


\section{Teología de la Iglesia y de la historia en Manuel Larraín}

La eclesiología previa al Concilio Vaticano II concentraba la actividad eclesial y apostólica en el ministerio ordenado. Desde diversos frentes, los movimientos de renovación en las décadas previas al Concilio fueron matizando un modelo de Iglesia que padecía de extrañeza frente al devenir histórico y de la aguda crisis en la comprensión de la naturaleza y misión de sus miembros. En estas décadas, el así llamado Movimiento Laical fue imprimiendo progresivamente -no sin tropiezosun carácter más inclusivo en materias de apostolado eclesial.

Sabido es que toda teología del laicado responde a una determinada comprensión de mundo y a un paradigma de Iglesia, sea este explícito o no. La teología pastoral de Larraín no fue la excepción, bajo ninguno de los dos aspectos. En su caso, la praxis eclesial determina esa doble comprensión. En su modelo de Iglesia se integraron los mejores elementos de la tradición, situándolos en una comprensión positiva de la historia y su devenir.

La así llamada "teología de las realidades terrenas" ${ }^{36}$ que se instalaría en el Concilio como una teología de la historia fue otro de los pilares que formaron el sistema teológico-pastoral. Por ello, revisaremos ahora algunos núcleos característicos de su teología de la Iglesia en y para el mundo.

\section{Eclesiología sin angelismos institucionalistas}

En el magisterio y en la teología, la naturaleza dual de la Iglesia había sido deficientemente tratada, al menos el periodo comprendido entre la fractura del cristianismo del siglo XVI y los albores del Concilio Vaticano II. La consideración de la realidad del órgano social, visible, histórico había absorbido la comprensión de la Iglesia en la teoría y, sobre todo, en la praxis.

En la teología de Larraín advertimos una atención directa al desarrollo del laico en su contexto y un eco de la mejor teología de la Iglesia desplegada en círculos teológicos, especialmente francófonos. En un esfuerzo por equilibrar a la societas perfecta, la recuperación de una eclesiología más mistérica, invisible y espiritual comenzó a tomar forma arraigada en la tradición bíblica y patrística. Tal equilibrio se hace patente en Larraín, en una intervención en aula, el 23 de octubre de $1963^{37}$ -cuando se discutía el capítulo De populo Dei del esquema De Ecclesia- en la cual instala el que será un acento en sus intervenciones.

\footnotetext{
${ }^{36}$ Larraín tenía especial cercanía intelectual con los ambientes francófonos teológicos. Sabemos que conocía el trabajo de Gustave Thils, teólogo de Lovaina quien publicara su Théologie des réalités terrestres en 1946 (Préludes) (versión castellana Teología de las realidades temporales. Buenos Aires: Desclée, 1948).

${ }^{37}$ Concilio Vaticano II, AS II, periodus II, pars III, 223-226.
} 
A juicio de Larraín, la descripción conciliar de la Iglesia debería cuidar un acercamiento más ajustado categorialmente a la existencia humana, enfatizando más en su visibilidad histórica con consolidación política. Aun bajo ciertos aspectos intemporales, "la Iglesia que peregrina en la Tierra es misterio encarnado en la historia en los hombres"38, y por ello resulta imperativo despojarse de todo angelismo institucionalista, es decir, de la absolutización de una suerte de fronteras institucionales perfectas, porque no solo está en juego su vida interna, sino que la relevancia de la Iglesia y de sus miembros va en progresiva decadencia ${ }^{39}$.

En contraste con ciertas eclesiologías donatistas del preconcilio, que acentuaban la santidad por ciertos criterios de pertenencia, Larraín situó el misterio de la Iglesia en un continuum protológicamente situado; y afirma que la historia de la Iglesia, desde el antiguo Israel, muestra que una visión angelical de la Iglesia desconoce su irrenunciable naturaleza histórica, pues necesita relevar y distinguir su naturaleza inmaculada y su condición pecadora, frágil, limitada; e insistirá por ello una y otra vez en que el binomio santa y pecadora, que le es intrínseca por su naturaleza dual, sea apropiadamente visibilizado también en la formulación magisterial. Leemos -en la misma intervención-que se requiere una ajustada, realista y equilibrada mirada sobre la institución que peregrina:

...la descripción de los mismos miembros del pueblo de Dios, los que hacen penitencia, que imploran la misericordia divina y que perdonan recíprocamente las cosas debidas, también ofrecerá más verdaderamente los aspectos humanos del misterio de la Iglesia a los hombres. ${ }^{40}$

La teología de los "miembros de la Iglesia" ocupó gran parte de la agenda conciliar. La pertenencia a la Iglesia cobró relevancia en paralelo al Movimiento Ecuménico, que revisitaba el tema con ojos interconfesionales. Para muchos resultaba prácticamente impresentable desconocer la gradualidad de pertenencia a la Iglesia, lo que ciertamente obligaba a rediseñar una teología del pueblo de Dios. En una eclesiología dibujada desde el eje binominal humano-divino/institución-carisma/corpóreo-espiritual, Larraín desarrolla su teología del pueblo de Dios no identificando exhaustiva y absolutamente el pueblo de la Iglesia, aunque el misterio de la Iglesia se desvele también en la representación de pueblo que se tenga.

Un pueblo peregrino, marcado por la historia, refleja de manera más justa y completa la realidad de la Iglesia y de su apostolado. La condición histórica no

${ }^{38}$ Ibíd.

${ }^{39}$ A cincuenta años de esa advertencia, podemos solo acordar con su juicio. La pretensión de angelismo institucionalista ha conducido a una pérdida progresiva de credibilidad en la Iglesia, especialmente en las décadas de escándalos públicos por abusos de conciencia y sexuales en su interior.

${ }^{40}$ Concilio Vaticano II, AS II, periodus II, pars III, 223-226. 
muestra únicamente precariedad, sino que la provee de posibilidades de despliegue en esa misma historia. Así, el peregrinaje es la gran oportunidad que tiene siempre la Iglesia de renovarse y adaptarse al tiempo: la reforma le es inherente ${ }^{41}$.

Contra todo institucionalismo, especialmente en su epistolario contemporáneo a los debates conciliares y al proceso de redacción de los documentos, Larraín desarrolla un paradigma de Iglesia arraigada en el movimiento evangelizador:

...la visión de una Iglesia misionera. Yo concuerdo plenamente con esta visión y creo que es la que corresponde a Chile. Ahora bien, me pregunto: ¿Hasta dónde concuerda, Iglesia misionera e institucionalismo? ¿Iglesia de evangelización e Iglesia de poder temporal? No voy a caer, ciertamente, ni en la visión de una Iglesia "pneumática", ni en la de una Iglesia solo "carismática". Pero la visión que el Concilio nos está dando de la Iglesia es ciertamente, mucho más [...] peregrina, pascual, escatológica [...] la conciencia que la Iglesia debe tener de sí misma no es otra que la de mirarse en Cristo. ¿No hay un cierto peligro en una visión de una Iglesia expresada, demasiado, en obras, más que en espíritu? 42

Larraín concibe una Iglesia en movimiento, sujeta al cambio ${ }^{43}$, una que puede adaptarse a nuevos lenguajes y signos de la época, sin descuidar por ello su esencia y tradición; y asegura que es precisamente en esta capacidad de adaptación donde se devela lo inamovible y esencial.

Por eso, frente a los cambios litúrgicos que afectaban la Iglesia estamentaria y positivamente, advertimos al lector - de manera casi anecdótica- que para Larraín no resultaba negativo, por ejemplo, cambiar la sotana por el clergyman, que en aquel momento causó grandes discusiones, ya que se consideraba que era un aspecto que podía desvirtuar la identidad del sacerdote. Larraín no titubeó al afirmar que, si bien este era un elemento externo que no definía la esencia sacerdotal, el hecho de adaptarlo a los tiempos sí decía algo sobre la identidad del sacerdote:

...se daría al vestir de clergyman su verdadero significado, que no es cuestión de alargar o acortar piezas de vestido, o ser más o menos hombre, etc., argumentos todos que a mi juicio nada valen, sino decir lo siguiente: a tiempos nuevos, estilos nuevos; el mundo de hoy requiere un sacerdote con ciertas características especiales, lo que hoy se llama un estilo de vida; ese estilo de vida

\footnotetext{
${ }^{41}$ Ibíd.

${ }^{42}$ Larraín, "Carta privada a Emilio Tagle (arzobispo de Valparaíso), Alberto Rencoret (obispo de Puerto Montt), José Santos (obispo de Valdivia), Francisco Valdés (obispo de Osorno) y Bernardino Piñera (obispo de Temuco), 28 de agosto de 1964". En ella expresa su temor de que la acción pastoral de la Iglesia chilena caiga en un institucionalismo vacío de espíritu evangélico.

43 Esta eclesiología dinámica se observa en el pontificado actual desde los albores y transversalmente expresado de diversas maneras en su magisterio: Iglesia en salida, llevar el Evangelio a la calle, Iglesia abierta al diálogo, etc.
} 
es tal (y aquí su desarrollo íntegro, dando su fundamento espiritual, hasta su expresión externa). De esta manera, yo creo que el cambio, lejos de producir males, traería grandes bienes... ${ }^{44}$

Transcurridos cincuenta años desde estas reflexiones, para nuestro obispo, hoy, el clergyman ya habría sido superado. Se trataba de atisbar hasta las últimas consecuencias de la doctrina que fraguaba el Concilio. En una entrevista sostiene:

...es menester que los católicos abran los ojos y se den cuenta del mundo en que viven. No todos lo saben, y otros parece que no quisieran saberlo... Yo pienso... que el Concilio va a mostrar más que nunca a la Iglesia unida, no solo en torno a la doctrina esencial, que ya lo está, sino sobre todo a la comprensión del mundo de hoy y a la solución que los cristianos debemos presentar. Muchas veces, el peligro mayor no es tanto la audacia de los enemigos de la Iglesia, cuanto la inconsciencia de los cristianos para comprender la misión que Dios exige de ellos en este mundo de hoy. ${ }^{45}$

Larraín consiguió penetrar en la responsabilidad apostólica conjunta que se deriva de un apropiado paradigma de Iglesia, situada en el mundo y para el mundo, en una historia que se despliega salvíficamente. Tal como se desarrolló el debate en la comisión conciliar en la que Larraín participó, la cual obtuvo como resultado el esquema de apostolatu laicorum, el apostolado laico se reinterpretó como la animación de las realidades temporales en comunión con la jerarquía de la Iglesia ${ }^{46}$. A esta cuestión nos referiremos en el apartado que sigue.

\section{La historia y sus acontecimientos: cuerdas vocales de la voz de Dios}

Larraín concibe al laico y su apostolado desde una comprensión particular del mundo y la historia, sin absorciones antropológicas pesimistas, y tensiona el devenir en clave soteriológica. En este sistema teológico, la encarnación del Verbo adquiere buena consistencia histórica en la comunidad de los discípulos insertos en la agrupación social donde el ser humano se despliega y evoluciona en y por medio de las cosas creadas.

En un ambiente doctrinal-teológico que desvalorizaba el progreso de los tiempos y miraba de forma pesimista el eventual intercambio entre mundo e Iglesia, la teología de las realidades terrenas le asignó consistencia a la historia y concibió los acontecimientos como signos de la voz de Dios. Para Larraín, el sentido trascendente es inmanente al mundo, dado que no hay historias superpuestas. El sobrenatural

\footnotetext{
${ }^{44}$ Larraín, “Carta a monseñor Bernardino Piñera (obispo de Temuco), 20 de marzo de 1963”.

${ }^{45}$ Ídem, Escritos completos. La Iglesia em su vida intima, 97.

${ }^{46}$ Para una mejor comprensión, ver a Zadra, "I movimenti ecclesiali e i loro statuti”, 7-21.
} 
aparece dentro del mundo ${ }^{47}$, ya sea por su origen creado, o por ser el escenario donde debe escucharse la voz de Dios que no viene desde fuera, sino desde dentro, desde sus acontecimientos, que son como cuerdas vocales de la voz divina. Solo hay verdadera escucha de la voz divina desde su Palabra, la cual se oye y ausculta en el contexto del mundo y no solo en la predicación:

No es suficiente escuchar la voz de los profetas con una fe transparente; también hay que escuchar por completo la voz de los tiempos con la razón que entiende. Se ha dicho sabiamente: en la voz del tiempo hay que escuchar la voz de Dios. Y Juan XXIII, de grato recuerdo, decía: hay que examinar atentamente las señales de los tiempos. ${ }^{48}$

La sintonía con la orientación impresa por el papa Juan no es casual. Larraín entendía desde la praxis que la fe cristiana es mediación histórica, y por ello influyó tan decisivamente en el desarrollo social chileno desde su tribuna como pastor del Maule. En efecto, su contribución al impulso de la reforma agraria en el Chile de los ańos sesenta ha quedado registrado en la historia nacional como un liderazgo eclesial en los esfuerzos por lograr la justicia social ${ }^{49}$; y en este trabajo involucró activamente tanto a la jerarquía como al laicado ${ }^{50}$.

\footnotetext{
${ }^{47}$ Muy en sintonía con la teología de Henri du Lubac en el contexto de la mejor llamada "nueva teología" (De Lubac, Surnaturel: études historiques).
}

48 Concilio Vaticano II, AS III, periodus III, pars IV, 184-186.

${ }^{49}$ La reforma agraria se comenzó a gestar al inicio de la década de los años 60 para mejorar de los niveles de producción agrícola a través de la lenta modificación del régimen de tenencia de la tierra. Para ello: "Los obispos chilenos acordaron encomendar una comisión técnica el estudio de una eventual colonización de las propiedades agrícolas pertenecientes a la Iglesia [...]. La noticia, propagada por la prensa nacional e internacional, fue recibida con gran satisfacción. Hoy día se ven los primeros frutos. Monseñor Manuel Larraín Errázuriz, obispo de Talca, en una sencilla ceremonia efectuada el jueves 28 de junio, en el fundo Los Silos de Pirque, anunció a las 17 familias que allí trabajan que el Obispado estaba ansioso de entregarles en propiedad la tierra que laboran..." (Gac, "La Iglesia chilena inicia la reforma agraria”, 362-364). En una carta de Manuel Larraín al cardenal Raúl Silva Henríquez, del 3 de agosto de 1963, expresa la envergadura de este evento para la Iglesia y la sociedad: "Reforma auténtica. No se trata, ni de un simple mejoramiento material (pueden darse casos en que bajo un buen patrón se esté mejor materialmente) ni de una simple repartición de tierras, sino de una reforma de estructuras en lo rural, en donde grupos de campesinos hechos propietarios de la tierra, realicen por ellos mismos, su incorporación en la actividad agrícola de Chile. Esta concepción supera (sin condenarlas) a otras formas de promoción agrícola, como la participación, la mediería, el arriendo, etc. Llamo auténtica esta reforma, por la sencilla razón que 'es reforma'. Es decir, cambio de formas. Las otras son remedios (muy legítimos, si se quieren), pero conservan las formas primitivas. En esta reforma nuestra hay propiedad personal, (no comunitaria, como se ha afirmado sin fundamento), pero sí, en gran parte (no exclusiva), trabajo común gracias a la cooperativa. Esa cooperativa, que constituye, junto con la propiedad familiar, el eje de nuestra reforma, es orientada por el organismo que dirige la reforma agraria de la Iglesia, este es Inproa, que le presta su cooperación técnica en lo agrícola, lo administrativo (economía y finanzas) y lo promocional".

${ }^{50}$ Sobre el involucramiento de los miembros de la Iglesia en la cuestión social en Chile, en el que colaboró decisivamente Larraín, ver a Botto, "Algunas tendencias del catolicismo social en Chile: reflexiones desde la historia”. 
La teología conciliar refrendó estas profundas intuiciones en Gaudium et spes. Larraín y el Concilio afirmaron que la voz de Dios solo se escucha en la voz del tiempo, con los propios matices culturales y contextuales. Un quehacer teológico que desconoce el contexto en el cual se despliega, se arriesga a no advertir la acción de Dios, y a no contribuir a la penetración, evolución y despliegue de la doctrina cristiana.

Naturalmente, en ese tiempo se precisa advertir que hay herida, pecado que necesita ser sanado. El rol de mediación eclesial en Larraín funciona también de manera inversa: él entiende que la Iglesia media en el proceso de sanación mediante la acción conjunta de la comunidad eclesial impulsada por la gracia de Dios en la historia. De ahí su insistencia en la especificidad del apostolado laico:

El apostolado en su propio ámbito no es una introducción indebida del asunto religioso en el asunto temporal, sino que más bien es la sanación y elevación del mismo asunto temporal. El apostolado conduce al mundo a su cumbre, la historia de los hombres a su fin, la creación al Reino de Dios. ${ }^{51}$

El orden temporal conserva su autonomía, y la mediación eclesial a través del apostolado laical no coacciona el desarrollo del tiempo en ningún sentido. En una comprensión adecuada de Iglesia, las realidades temporales adquieren densidad escatológica mayor, tensionando el cumplimiento definitivo del Reino. En la eclesiología de Larraín hay un reconocimiento explícito de la absoluta soberanía de Dios y de su acción por medio de la actividad eclesial que verifica en la historia la realidad escatológica del Reino, como un germen de comunión en sentido vertical y horizontal $^{52}$. El Reino es de Dios: él es quien eleva una realidad herida mediante la praxis concreta de los fieles cristianos.

La antropología del obispo de Talca es también muy optimista, al sostener que es precisamente el ser humano quien tiene la potencialidad de reordenar toda la realidad temporal según Cristo. Y sostiene que el verdadero ser humano es el que no abandona el mundo, sino quien busca desarrollarlo verdadera y plenamente ${ }^{53}$. Lejos de separar dos esferas, Larraín percibe una analogía entre la encarnación y la vocación apostólica. Dios, que es solidario con el mundo, envía a su Hijo para rescatarlo y, si bien el origen y fuente de la actividad apostólica de la Iglesia es Cristo ${ }^{54}$, el escenario de la encarnación y del apostolado de sus discípulos es la realidad temporal. Esta

\footnotetext{
${ }^{51}$ Concilio Vaticano II “AS III, periodus III, pars IV”, 184-186.

${ }^{52}$ La eclesiología dibujada en la constitución dogmática Lumen gentium, especialmente para estos efectos, en los parágrafos 1 y 5 , reciben esta teología de la Iglesia.

${ }^{53}$ Concilio Vaticano II, AS III, periodus III, pars IV, 184-186.

${ }^{54}$ Ídem, "Decreto Apostolicam actuositatem sobre el apostolado de los laicos”, párr. 4.
} 
no debe ser minusvalorada o ignorada o, peor aún, ser considerada como el enemigo permanente de la Iglesia.

Al comprender la realidad temporal como lugar de manifestación de lo divino, y al escuchar la voz de Dios en la voz del tiempo ${ }^{55}$, adquiere sentido, consistencia y relevancia lo que Larraín llama el "ámbito propio" del laico ${ }^{56}$, que es el mundo en el que también peregrina la Iglesia ${ }^{57}$. El escenario de la encarnación es el mundo y la historia: ahí es donde resuena la voz de Dios, en una realidad que no se desarrolla por sí misma sino que requiere de la activa intervención del ser humano que la pueda reconducir a su fin, desde la pluralidad que le es intrínseca.

El "ámbito propio del laico" no es la comunidad eclesial, en su concreción y devenir, sino - por el contrario-el mundo con todos sus logros, avances, preocupaciones y dificultades ${ }^{58}$. La obertura de Gaudium et spes recoge bellamente esta teología.

Larraín enfatiza en esta unidad entre creación y encarnación, que él llama sistemáticamente "unidad de conciencia de los apóstoles" 59 , la cual produce y mantiene la unidad entre la Iglesia y de las realidades creadas; y sostiene que la conciencia del laico sobre su actividad apostólica es extensiva, un quehacer que opera como mediación en el reconocimiento y eventual elevación de las cuestiones temporales.

Por medio del apostolado, el laico realiza su vocación humana en la historia y lleva el mundo a su progreso, que en Larraín supone verdadera humanización. El desarrollo humano debe ser el horizonte del apostolado eclesial.

El progreso es una actividad humana e implica la responsabilidad y el amor del hombre; no puede ser reducido a una organización de asistencia social o de limosnas; es, por el contrario, la mutua comunicación de las personas y de los pueblos para realizar convenientemente la vocación humana en la historia, la que es para todos la única vocación para humanizar nuestro planeta, para que sea una patria digna del hombre, el que, hecho a la imagen de Dios. ${ }^{60}$

El progreso compromete a la persona. Larraín no concibe un cristianismo sin esta dimensión social que brota de un corazón evangélico que debe impulsar al laico al compromiso en la construcción de la civilización.

55 Ídem, AS III, periodus III, pars IV, 184-186.

${ }^{56}$ Ibíd.

${ }^{57}$ La recepción de esta teología del laicado se advierte no solo en el decreto sobre el apostolado laico, sino también en el capítulo IV de Lumen gentium, especialmente en los Nos. 30-31.

${ }^{58}$ Concilio Vaticano II, AS III, periodus III, pars IV, 184-186.

${ }^{59}$ Ibíd.

${ }^{60}$ Ídem, AS IV, periodus IV, pars III, 373-375. 
Toda reforma social, por más avanzada que sea, debe comenzar por la reforma interior del hombre. Si no hay un concepto evangélico de la existencia y de los problemas que la vida nos ofrece, es difícil que nosotros podamos tener una clara visión de un orden social cristiano ${ }^{61}$. No por esto desprovee al laicado de su irrenunciable compromiso eclesial, como institución histórica, sujeta al cambio, a la reforma y renovación: la Iglesia requiere del compromiso de todos sus miembros.

El laico se transforma en un puente que lleva el mensaje del Evangelio, el Reino, al mundo, y las "cuestiones" del mundo a la Iglesia ${ }^{62}$. El cristiano es miembro natural de su propio ámbito ${ }^{63} \mathrm{y}$, en cuanto apóstol, es enviado por la comunidad eclesial a ese mismo ámbito. Urgido, en una ocasión, a pronunciarse acerca del "supuesto silencio de la Iglesia" en Chile ${ }^{64}$, Larraín refuerza su confianza en los signos de la historia o la voz de los tiempos y, a la vez, en la eficacia de la acción concreta o praxis del laicado. Conviene poner atención a los detalles, anota.

Emilio Tagle ${ }^{65}$, entonces arzobispo de Valparaíso, en carta enviada a Larraín, quien se desempeñaba como presidente del $\mathrm{Celam}^{66}$, critica que la Iglesia no se pronunciara ante la inquietante situación política que vivía Chile en ese momento. A esta crítica, Manuel responde cordialmente explicándole los criterios de su actuación ${ }^{67}$ : el primero es de orden de "competencia", al llamar a "creer en los técnicos", quienes advirtieron sobre los grandes inconvenientes que podrían producirse. Además, invita a Tagle a "dejar que nuestros laicos actúen, porque ellos también son Iglesia, dejar que ellos también expongan la doctrina que el magisterio les ha entregado, dado que lo han hecho y lo están haciendo bien".

Se trataba de reivindicar la autonomía de los laicos como sujetos activos de recepción del depositum fidei, capaces de discernir adecuadamente, con criterios evangélicos y eclesiales la praxis en la arena pública. En un analogado teológico,

${ }^{61}$ Larraín, "Carta a Juanito, 4 de mayo de 1961".

${ }^{62}$ Concilio Vaticano II, AS III, periodus III, pars IV, 184-186.

${ }^{63}$ Ibíd.

${ }^{64}$ En 1964, a meses de las elecciones entre Eduardo Frei Montalva y Salvador Allende Gossens. La disputa entre un eventual gobierno falangista a uno socialista tenía al catolicismo chileno esperando una voz episcopal más corporativa. El reclamo a Larraín se podría haber extendido al resto del cuerpo de los obispos.

${ }^{65}$ Emilio Tagle (1907-1991), sacerdote chileno nombrado obispo auxiliar del cardenal José María Caro en enero de 1958. A finales del mismo año, al morir el cardenal Caro, Tagle es nombrado administrador apostólico de la Arquidiócesis de Santiago. En 1961es designado arzobispo de Valparaiso y con ello ejerce como gran canciller de la Pontificia Universidad Católica de Valparaiso, a lo que renuncia en mayo de 1983 por razones de salud. Fallece el 5 de septiembre de 1991 en Santiago de Chile.

${ }^{66}$ Conferencia del Episcopado Latinoamericano, fundada por Dom Hélder Câmara y Manuel Larraín.

${ }^{67}$ Larraín, “Carta a monseñor Emilio Tagle, 4 de julio de 1964”. 
Larraín considera que así como la gracia realiza a la naturaleza, el apostolado realiza la vocación del ser humano en el mundo, que es colaborar en la ordenación de la realidad temporal hacia el Reino de Dios.

La unidad de la conciencia de los "apóstoles"/discípulos/laicado se corresponde a la unidad entre creación y encarnación, y a la unidad entre la Iglesia y el mundo. Si el laico pertenece a una doble comunidad -la eclesial y la sociedad civil- opera y debe operar conectando, como lo hace un puente entre dos puntos inconexos. “ $\mathrm{iEs}$ la hora de los laicos!" decía Larraín en la década de los sesenta ${ }^{68}$, al percibir que el declive observado en la misión de la Iglesia se debía a que no se le había dado al laico el lugar que le correspondía: "El fin es uno, la batalla es una, la Iglesia es una, el laicado es uno, y la jerarquía es una; las tareas, sí son diversas, y es ahí donde hay que hacer la distinción" ${ }^{\prime 9}$.

Larraín enfatiza en el valor de la teología del sacerdocio bautismal como el lugar desde el cual teológicamente es admisible la igualdad fundamental de todos los fieles cristianos y la distinción de funciones y roles a partir de los ministerios diversos; aboga por un laicado consciente y actualizado, eclesial y civilmente, que se haga cargo también de la propia asociación eclesial que los representa.

Es necesario nombrar un Consejo de Laicos, que dirijan y orienten la Acción Católica, porque de otra manera vamos a quedar, nuevamente, con una Acción Católica entregada totalmente en manos de los sacerdotes, lo que no debe ser. Este Colegio de Laicos, llámese Junta Diocesana, o como quieran llamarlo, debe tener la verdadera dirección. Yo lo integraría con un representante, no solamente de los movimientos, sino que de los sectores, y aquí es donde yo creo que puede producirse la unión, entre lo ambiental, y lo que podríamos llamar, parroquial, o postmisionero. ${ }^{70}$

En el esfuerzo de los laicos por mantenerse actualizados y comprometidos en las cuestiones eclesiales y civiles, Larraín comprende que la institución no resulta siempre ser un canal seguro y expedito. Muy por el contrario, a su juicio, el desfase con el que las instituciones avanzan respecto del mundo tiende a enclaustrar al laico en un núcleo cerrado y anacrónico que dificulta el desarrollo del apostolado según las necesidades propias de su ámbito. La institución puede oscurecer el rostro de sus miembros. Parecería que se encuentra entonces como entre dos ciudades -el mundo y la Iglesia-, pero para Larraín el laico no está en un "entre dos" sin patria, porque su

${ }^{68}$ Concilio Vaticano II, $A S$ III, periodus III, pars IV, 184-186.

${ }^{69}$ Larraín, "Carta a Santiago Brurón, 23 de junio de 1964".

${ }^{70}$ Ídem, “Carta a Enrique Alvear, 26 de febrero de 1964”. Resultaba muy liberal esta postura, toda vez que la Acción Católica fue un organismo eclesial para el laicado completamente dirigido, orientado y liderado por la jerarquía eclesiástica. Ver a Concilio Vaticano II, $A S$ III, periodus III, pars IV, 184-186. 
lugar es la historia, y precisamente por la unidad entre creación y encarnación, por la "unidad de conciencia de los apóstoles" ${ }^{11}$, debería producirse la unidad de la Iglesia y el mundo.

No por ello se identifican las tres entidades: la Iglesia no es el mundo, el mundo no es el laico, el laico no es la Iglesia ni tampoco el mundo; no se producen absorciones teológicas de una entidad en otra. ¿Dónde se produce la unidad? Ellas encuentran su despliegue y plenitud en la mutua comunión que se produce al escuchar la voz de Dios que resuena en los acontecimientos del mundo. Se trata de un movimiento que trae un cambio "pastoral" y no tan solo "doctrinal" en la Iglesia, y por lo mismo, presenta una Iglesia viva, que puede y debe salir al encuentro de la historia de un modo que resulte relevante. Es un cambio interno y metodológico de acceso al mundo, a la historia, a la realidad eclesial encarnada ${ }^{72}$.

\section{Vagos ecos de esa teología del laicado en el posconcilio chileno}

El Sínodo de Obispos de 1987 dio lugar a la promulgación de la exhortación apostólica Christifideles laici. Ella constituye la primera recepción de la naturaleza y del rol del laicado según Apostolicam actuositatem. En este contexto, en junio de 1988, el Instituto Pastoral de Estudios Superiores Blas Cañas, creado e impulsado por el arzobispo de Santiago, cardenal Raúl Silva Henríquez ${ }^{73}$, realizó su primera semana teológica bajo el tema "La vocación y misión del laico en el Chile de hoy". En 1989, ello dio lugar a una publicación conjunta interdisciplinar titulada Laicado: Iglesia, cultura y sociedad $^{14}$, que expone de manera notable la recepción chilena del magisterio católico en ambientes eclesiales intelectuales.

Dos preocupaciones se explicitan en la obra: una, la relación del laico con la vida sociopolítica (en contexto de dictadura militar): perspectiva ad extra; y la otra, el rol del laico en la Iglesia chilena: perspectiva ad intra. Respecto de la primera, la pregunta se centra en cómo debería comportarse un católico en este ambiente de fragmentación y de sistemática violación de los derechos de las personas ${ }^{75}$, no solo al

${ }^{71}$ Ídem, AS III, periodus III, pars IV, 184-186.

${ }^{72}$ Muy iluminador resulta el artículo de Carlos Schickendantz sobre el lugar que ocupa la teología de los signos de los tiempos conciliar, en el proceso de comprensión y argumentación teológica en el posconcilio (Schickendantz, "Un cambio en la ratio fidei: asociación (aparentemente ilícita) entre principios teológicos y datos empíricos”, 157-184).

${ }^{73}$ Fundado en plena dictadura militar, en 1982, como institución educativa perteneciente a la Congregación Salesiana. Buscaba dar una solución a los jóvenes de escasos recursos que deseaban entrar a la educación superior a través de la formación superior técnica. Desde 1990, con el retorno a la democracia en Chile, el Instituto es reconocido como Universidad Blas Cañas, que es el nombre de su fundador.

${ }^{74}$ Barrios Valdés (ed.), Laicado: Iglesia, cultura y sociedad.

75 Ibíd., 50 y 54. 
hacerse cargo de esa realidad sino al analizar las responsabilidades de los cristianos en general y los católicos en particular en la decantación de este proceso. Respecto de la segunda, se articula una respuesta que centra el rol del laico en una perspectiva eclesiológica más amplia. Se determina que esa comprensión y modelo de Iglesia que se han gestado en las comunidades eclesiales de base, que es menos piramidal, más participativa y comunional, ha dado origen a una comprensión de laicado más consciente y crítica de las estructuras eclesiales en las que vive su $\mathrm{fe}^{76}$.

El Sínodo había sostenido que el papel del laico no es -bajo ningún aspecto"sustituir" al clero, y había planteado una distinción clara entre vocación y misión. El llamado había sido a la comunión eclesial, por un lado, y a la misión en el mundo, por el otro. ${ }^{77}$ La vocación antecede a cualquier encargo concreto, da un status con impronta sacramental-bautismal ${ }^{78}$, y deja en plano de igualdad la dignidad frente a otras vocaciones posibles. La "secularidad" de la vocación laical se inscribiría en la sacramentalidad de la Iglesia, pues mientras en más ambientes estén presentes los laicos, habrá más presencia de la Iglesia y de Cristo ${ }^{79}$.

En un ambiente más pastoral estas cuestiones tomaron formas diversas. Para efecto del presente artículo basta enunciar que, en términos generales, la doctrina sigue en proceso de recepción, y lo ejemplificaremos en la forma como la Conferencia Episcopal Chilena, $\mathrm{CECH}$, ha abordado el tema en sus últimos documentos pastorales. En sus "Orientaciones pastorales 2001-2005" ${ }^{80}$ sigue siendo necesario enfatizar en el rol del laico como evangelizador de la cultura (No. 122). No obstante, ahí la Iglesia chilena intenta hacerse cargo de la proliferación de diversos movimientos laicales a lo largo del país ${ }^{81}$, cuestión presente en el plan de trabajo de la Comisión Nacional de Laicos de la CECH en el periodo 2000-2008.

\footnotetext{
${ }^{76}$ Ibíd., 46.

${ }^{77}$ Ibíd., 85.

${ }^{78}$ Ibíd., 87.

79 "La ciencia y la tecnología, el medio ambiente, la participación política, la doctrina social de la Iglesia, la pobreza, la educación, la formación de personas, la catequesis, la familia, el trabajo y la cultura del trabajo" (ibíd., 92).

${ }^{80}$ Conferencia Episcopal de Chile, "Orientaciones pastorales 2001-2005”.

${ }^{81}$ Para los movimientos laicales posconcilio hay abundante literatura. Se consideran algunas como fruto del Concilio y otras como una aplicación no tan bien entendida del mismo. Ver, por ejemplo, a John Paul II, "Message for the World Congress of Ecclesial Movements and New Communities (27 May 1998)"; Pontificium Consilium pro Laicis, Movements in the Church: Proceedings of the World Congress of the Ecclesial Movements 16. Este sostuvo: [The movements] "represent one of the most significant fruits of that springtime in the Church which was foretold by the Second Vatican Council". Ver también a Etxeberría, "Los movimientos eclesiales en los albores del siglo XXI", 577-616; Rocca, L'Opus Dei. Appunti e documenti per una storia; y Fondi y Zanzucchi, Un popolo nato dal Vangelo. Chiara lubich e $i$ focolari, entre otros.
} 
Desde esas "Orientaciones pastorales", la Comisión se propone "convocar a movimientos para reflexionar, sensibilizar y elaborar material para los agentes pastorales" (No. 97); promover encuentros para compartir e intercambiar experiencias de misión (No. 98); establecer coordinación nacional con movimientos a través de encuentros y favorecer la formación de una coordinadora diocesana de movimientos (No. 110); convocar a los encargados diocesanos de laicos (No. 121), particularmente para dar buena formación sobre la vocación y misión del laico en las diversas realidades temporales (No. 211). Esto debe ir de la mano con estimular el estudio y la reflexión en lo relativo a la identidad, vocación y misión de los laicos y de la doctrina social de Iglesia (Nos. 227, 228, 229).

La Comisión fue consciente de que no siempre es posible para los laicos desempeñar su servicio en las diócesis; por ello se propuso promover encuentros con los encargados diocesanos y con los movimientos para fortalecerlos en su servicio a su Iglesia local (No. 231). Esto fue imperativo hasta 2008. Los acentos evidenciaban la todavía pobre recepción de Apostolicam actuositatem.

El laicado chileno, especialmente de algunos ambientes eclesiales, fue muy activo en la defensa de los derechos humanos durante el periodo político contemporáneo a Christifideles laici. Dirigentes de organizaciones sociales en tiempos de la dictadura eran activos miembros de sus comunidades eclesiales. Se puede decir, entonces, que la doctrina conciliar de la inserción del laico en el ámbito secular fue rápidamente entendida y puesta en práctica. Sin embargo, también se puede sostener que el riesgo de caer en un activismo social desvinculado de su carácter evangélico fue grande y ello trajo consigo un problema eclesiológico serio. Cuando el laico se encontraba empoderado en ambientes seculares, veía a la vez un trato menos adulto en su comunidad eclesial. Su inserción en ambientes eclesiales se redujo, en muchos casos, a su rol en actividades de suplencia del ministerio ordenado. En las últimas "Orientaciones pastorales" de la CECH, para el periodo 2014-2020, tituladas "Una Iglesia que escucha, anuncia y sirve" ${ }^{82}$, se evidencia que la Iglesia chilena reflexiona críticamente en torno del tema del liderazgo y del rol laical desde la corresponsabilidad ${ }^{83}$.

\footnotetext{
${ }^{82}$ Conferencia Episcopal de Chile, "Orientaciones pastorales 2014-2020”.

83 "Necesitamos renovar en profundidad el ejercicio del liderazgo en la Iglesia a fin de hacerlo más acorde al modelo del Buen Pastor (ver Jn 10,1-18) [...]. Todos los creyentes somos corresponsables, aunque sea en diversos niveles y modos, de la vida de nuestra Iglesia. Quisiéramos fortalecer aún más la corresponsabilidad laical en diversos ámbitos de la vida eclesial. De modo muy especial necesitamos revisar el rol de la mujer en la vida y en las estructuras de la Iglesia, ya que con frecuencia ocupa un lugar que no da cuenta de modo apropiado de su dignidad ni de la especificidad de su aporte a la vida de la Iglesia" (Conferencia Episcopal de Chile, “Orientaciones pastorales 2014-2020”, Parte II: “Una Iglesia que anuncia y celebra”, g).
} 
Releer esto a la luz del llamado "Testamento pastoral al episcopado de Chile", de monseñor Larraín al final de sus días, en 1966, hace pensar que la crisis en el apostolado laico que describió entonces con fineza, ha persistido por décadas ${ }^{84}$. El núcleo del problema -a juicio de Larraín- era la "falta de distinción clara entre un apostolado de evangelización y uno de orden temporal", ambos necesarios, pero que debían distinguirse uno del otro, y ser estructurados y coordinados en lo que él llamó "pastoral de conjunto", o "política pastoral" que se hiciera cargo de los problemas de tres ambientes especialmente: juvenil, obrero y rural ${ }^{85}$. A pesar de la incorporación del discernimiento comunitario y la corresponsabilidad en las últimas orientaciones, esa corresponsabilidad laical, la distinción de órdenes para una penetración más relevante eclesial y socialmente, continúa siendo muy deficitaria.

Se entiende que la credibilidad de la Iglesia se resiente si sus miembros no viven de acuerdo con su dignidad, no ejercen su vocación y no cumplen con su misión. Tenemos muchas tareas pendientes.

\section{Reimaginar el laicado: cuestiones conclusivas}

El decreto Apostolicam actuositatem quiso estimular el servicio de la Iglesia mediante todo el laicado, en una perspectiva eclesiológica más amplia, ya no jurídica, tal como lo entiende Lumen gentium. Aquel cimenta su enseñanza en la incorporación bautismal al sacerdocio común de Cristo, y por tanto, no ve a los laicos como sujetos pasivos de pertenencia eclesial, sino como activos miembros del cuerpo de Cristo. Los debates preconciliares ya habían puesto en discusión una comprensión amplia de apostolado, que el documento adopta. No solo se atiende a la evangelización directa y a la santificación del mundo, sino también a la atención consciente de la historia en la cual resuena la voz de Dios y el Evangelio debe penetrar con su fuerza transformadora.

El apostolado laico no necesita de una autorización canónica; ya no es considerado una fuerza auxiliar de la jerarquía ${ }^{86}$. De este modo se dio un vuelco en la comprensión de su naturaleza y su misión, y eso es sin duda un progreso eclesiológico notable. Este solo hecho generó gran entusiasmo en el posconcilio. Sin embargo, dicho entusiasmo tal vez rayó con un optimismo ingenuo que vemos ilustrado en parte en el caso chileno, porque se han debido levantar los mismos temas debatidos en el periodo conciliar una y otra vez.

\footnotetext{
${ }^{84}$ Larraín, Archivo Obispado de Talca [no clasificado] 17 pp. Larraín comienza las 17 carillas de un manuscrito sosteniendo que esas líneas pretenden ser algunas reflexiones sobre el momento actual de la Iglesia en Chile y "las líneas fundamentales de apostolado que a mi juicio se precisan".

${ }^{85}$ Ibíd.

${ }^{86}$ Carriquiry, "Il laicato dal Concilio Vaticano II ad oggi: esiti positivi, difficoltà e fallimenti”, 73.
} 
El decreto contiene una enseñanza rica y clara, que ha permeado más en la vida de los nuevos movimientos laicales pero poco en la vida de cada fiel laico y en las estructuras de algunas iglesias diocesanas. También se observa lo contrario: el laico pasivo que actúa como mero receptor pasivo de ciertos servicios eclesiásticos.

Creemos que, si bien el decreto tuvo muy poco impacto en la vida de los fieles laicos, se presenta en el quincuagésimo aniversario de su promulgación como una oportunidad de renovación, de acuerdo con el espíritu del papa Francisco. La doctrina conciliar no está caduca; está más vigente que nunca. El carácter secular de la misión del laico no es un mero dato exterior, ni algo puramente sociológico, sino más bien algo intrínsecamente teológico-eclesial.

$\mathrm{Al}$ releer algunos documentos de Larraín, hemos advertido con más hondura los alcances de la teología/doctrina conciliar del laicado que él colaboró a fraguar. Quisiéramos, para concluir, reimaginar al laicado católico hasta un nuevo Concilio.

Imaginamos a laicos más y mejor formados en las cuestiones "del tiempo, la historia" y "de la Iglesia” para que -como sostuvo Larraín- ejerzan con sentido su rol de mediación entre la institución civil y la religiosa. Por un lado, la adecuada penetración en las realidades temporales requiere consistencia, y por otro, la renovación de las estructuras de la Iglesia obliga a conocerla bien.

Desde acá, imaginamos a laicos activamente participando en el "diseño" institucional permanente al que debe ser sometida la comunidad eclesial, de modo que se ajusten más al tiempo y a las diversas culturas; laicos que operen como un "observatorio" permanente donde se relevan eclesialmente los temas de la agenda pública (la voz de Dios en el tiempo) y, a la vez, donde se instalan en la agenda pública temas de relevancia religiosa y eclesial.

Quisiéramos, finalmente, que el apostolado laico fuera revisitado desde las categorías eclesiológicas fundamentales del Concilio, tal como lo está haciendo gradualmente el Papa actual. Desde un paradigma de Iglesia-communio, el ministerio bautismal laical adquiere plena vigencia y relevancia, y hay claridad de que la misión apostólica es de la Iglesia y no solo de algunos de sus miembros. La reforma eclesial requiere mayor y mejor presencia laical en todas las estructuras de la vida eclesial.

\section{Bibliografía}

Barrios Valdés, Marciano (ed.). Laicado: Iglesia, cultura y sociedad. Santiago de Chile: Instituto Profesional de Estudios Superiores Blas Cañas. Centro TeológicoFilosófico, 1989.

Botto, Andrea "Algunas tendencias del catolicismo social en Chile: reflexiones desde la historia". Teología y vida XLIX (2008): 499-514. 
Carriquiry, G. M. "Il laicato dal Concilio Vaticano II ad oggi: esiti positivi, difficoltà e fallimenti”. En Il fedele laico. Realtà e prospettive, editado por L. Navarro y F. Puig, 67-111. Milán: Giuffré Editore, 2012.

Concilio Vaticano II. (2o: 1962-1965). Acta Synodalia Sacrosancti Concilii Oecumenici Vaticani II. Vol. II, periodus II, pars III. Ciudad del Vaticano, 1963. . Acta Synodalia Sacrosancti Concilii Oecumenici Vaticani II. Vol. III, periodus III, pars IV, 1964.

. Acta Synodalia Sacrosancti Concilii Oecumenici Vaticani II. Vol. IV, periodus IV, pars III. Ciudad del Vaticano, 1965.

. "Constitución dogmática sobre la Iglesia Lumen gentium". En Concilio Ecuménico Vaticano II. Constituciones, decretos y declaraciones, 49-156. Madrid: Biblioteca de Autores Cristianos, 2012.

. "Decreto Apostolicam actuositatem sobre el apostolado de los laicos". En Concilio Ecuménico Vaticano II. Constituciones, decretos y declaraciones, 487-527. Madrid: Biblioteca de Autores Cristianos, 2012.

Conferencia Episcopal de Chile. "Orientaciones pastorales 2001-2005". Iglesia.cl, http://documentos.iglesia.cl (consultado el 14 de septiembre de 2016).

. “Orientaciones pastorales 2014-2020”. Iglesia.cl, http://www.iglesia.cl/ especiales/oopp2014-2020/ (consultado el 14 de septiembre de 2016).

Congar, Yves. Diario del Concilio. Milano: San Paolo, 2005. . Jalons pour une théologie du laïcat. Paris: Du Cerf, 1954.

De Lubac, Henri. Surnaturel: études historiques. Paris: Aubier, 1946.

Etxeberría, J. J. "Los movimientos eclesiales en los albores del siglo XXI". Revista española de Derecho Canonico 58 (2001): 577-616.

Ferrari, Liliana. Una storia dell'Azione cattolica. Gli ordinamenti statutari da Pio XI a Pio XII. Genova: Marietti, 1989.

Gac, Gustavo. "La Iglesia chilena inicia la reforma agraria". Revista Mensaje 111 (1962): 362-364.

John Paul II. "Message for the World Congress of Ecclesial Movements and New Communities (27 May 1998)". Vatican, https://w2.vatican.va/content/ john-paul-ii/en/speeches/1998/may/documents/hf_jp-ii_spe_19980527_ movimenti.html (consultado el 14 de septiembre de 2016).

Lanne, Emmanuele. "La contribution du cardinal Bea à la question du baptême et l'unité des chrétiens”. Irénikon 55 (1982): 474-475. 
Larraín, Manuel. Acción Católica y realidades modernas. Santiago: Club de Lectores, 1947.

. "Carta a Enrique Alvear, 26 de febrero de 1964". Archivo Obispado de Talca [en proceso de clasificación, no publicado].

. "Carta a Juanito, 4 de mayo de 1961". Archivo Obispado de Talca [en proceso de clasificación, no publicado].

. "Carta a monseñor Bernardino Piñera (obispo de Temuco), 20 de marzo de 1963”. Archivo Obispado de Talca [en proceso de clasificación, no publicado]. . "Carta a monseñor Emilio Tagle, 4 de julio de 1964". Archivo Obispado de Talca [en proceso de clasificación, no publicado].

. "Carta privada a Emilio Tagle (arzobispo de Valparaíso), Alberto Rencoret (obispo de Puerto Montt), José Santos (obispo de Valdivia), Francisco Valdés (obispo de Osorno) y Bernardino Piñera (obispo de Temuco), 28 de agosto de 1964". Archivo Obispado de Talca [en proceso de clasificación, no publicado]. . "Carta a Santiago Brurón, 23 de junio de 1964". Archivo Obispado de Talca [en proceso de clasificación, no publicado].

- "Discurso del asesor general de la A.C. Chilena en la sesión de clausura de la III Semana Interamericana de A.C.”. Ecclesia 12 (1954): 1-15.

- El cristiano frente al mundo moderno. El apostolado del ambiente. Santiago: Casa Hogar San Pancracio, 1949.

. Escritos completos. La Iglesia en el mundo. Editado por Pedro de la Noi. Santiago: Ediciones Paulinas, 1976.

. Escritos completos. La Iglesia en su espiritualidad. El laico cristiano. Editado por Pedro de la Noi. Santiago: Ediciones Paulinas, 1976.

. Escritos completos. La Iglesia en su vida intima. Editado por Pedro de la Noi. Santiago: Ediciones Paulinas, 1976.

. Hacia una espiritualidad del laicado. Santiago: Paulinas, 1957.

. "Testamento al Episcopado de Chile (1966)". Archivo Obispado de Talca [en proceso de clasificación, no publicado].

. "Testamento pastoral". Diocesis de Talca, http://diocesisdetalca.cl/especial_ $\mathrm{mml} / 6$ _Testamento_Pastoral_de_Mons_Manuel_Larrain.pdf (consultado el 14 de septiembre de 2016).

Fondi, Enzo Maria y Michele Zanzucchi. Un popolo nato dal Vangelo. Chiara lubich e i focolari. Cinisello B.: San Paolo, 2003. 
McGrath, Marcos. "Los laicos en la Iglesia". Archives University of Notre Dame, Collection Marcos McGrath CMCG 5/04, 4. 22 Octubre de 1963.

. "Segunda Sesión del Concilio Ecuménico Vaticano II. CECH". Archives University of Notre Dame, Collection Marcos McGrath CMCG 16/05, 4. 4 de Diciembre de 1963.

Pesce, Dante. “Pensamiento social de monseñor Manuel Larraín Errázuriz”. Tesis para la obtención de Licenciatura en Historia, Pontificia Universidad Católica de Chile, Santiago, 1995.

Pontificium Consilium pro Laicis. Movements in the Church: Proceedings of the World Congress of the Ecclesial Movements. Vatican City: Libreria Editrice Vaticana, 1999.

Rocca, Giancarlo. L'Opus Dei. Appunti e documenti per una storia. Milano: Paoline, 1985.

Schickendantz, Carlos. "Un cambio en la ratio fidei: asociación (aparentemente ilícita) entre principios teológicos y datos empíricos". Teología y vida 57, No. 2 (2016): 157-184.

Steinmaus-Pollak, Angelica. Das als katholische Aktion organisierte Laienapostolat: Geschichte seiner Theorie und seiner kirchenrechtlichen Praxis in Deutschland. Würzburg: Echter, 1988.

Stuven, Ana María. "El 'Primer catolicismo social' ante la cuestión social: un momento en el proceso de consolidación nacional". Teología y vida XLIX (2008): 483-497.

Witte, J. “The Question of Baptism and the Unity of Christians”. En Simposio Card. Agostino Bea 16-19 dic. 1981, 223-230, Rome, 1983.

Zadra, Bárbara. "I movimenti ecclesiali e i loro statuti." Tesi Gregoriana, Serie Diritto Canonico, Pontificia Universidad Gregoriana, Roma, 1997. 